Check for updates

London

Cite this as: $B M J 2021 ; 372: \mathrm{n} 247$ http://dx.doi.org/10.1136/bmj.n247 Published: 27 January 2021

\title{
Palliative care: Experts call for major reforms as pandemic accelerates demand by 20 years
}

\section{Shaun Griffin}

Experts at a leading charity have made an urgent call for reforms to the UK's palliative care system, as demand during the covid pandemic reached levels that had not been expected until 2040.

More than half a million people in England and Wales were predicted to need palliative or end-of-life care by $2040,{ }^{1}$ but this level of demand will have been achieved in 2020, said researchers from Cicely Saunders International. ${ }^{2}$ They said that too many people who had life limiting illnesses or were approaching death were spending unnecessarily long periods in hospital without being offered alternatives, when most would prefer to die at home. ${ }^{3}$

Around $80 \%$ of people would prefer to die at home or in their place of residence, but in some parts of England and Wales less than $50 \%$ do so. To help meet people's needs the authors called for face-to-face care, including symptom management, seven days a week in hospitals, as well as 24/7 support and advice in the community. Prompt access to therapeutic, nursing, and pharmacy services to support people in their homes is also needed, they said.

Choice at the end of life is being compromised by poor coordination between health and social care and a shortage of expertise, the report said. It advised that everyone in this situation should have a named senior clinician and care coordinator.

The researchers also highlighted an independent, government commissioned review of choice in end-of-life care, ${ }^{4}$ which estimated that £150m ( $€$ 170m; $\$ 206 \mathrm{~m}$ ) was needed to provide a "national choice offer" to patients and carers for end-of-life care. This would help to pay for timely intervention and a defined contact with a trained professional to support delivery of self-care.

Other recommendations in the report's seven point action plan include increased investment in social and community care services, a strategic approach to training, and a system of continuous learning and improvement. The authors called for an increase to the $0.2 \%$ of the medical research budget that is currently dedicated to developing better ways for caring for terminally ill patients.

\section{A human right}

Irene Higginson, scientific director at Cicely Saunders International, said, "The covid-19 pandemic has made it clear that, when the demand for health and social care services goes up, the provision of palliative care falls short. It's vital that we learn from this experience and implement the changes necessary to secure high quality palliative care for all patients.”
Kathryn Mannix, a palliative care physician, said, "Access to support for wellbeing, person centred care, and excellent symptom management should be seen as a human right throughout life. It is time to recognise that people approaching death have the same rights and to fund the services that will allow them to live well for the remainder of their lives."

Gurch Randhawa, professor of diversity in public health at the University of Bedfordshire, said, "This report provides a welcome focus on the urgent need to improve access and quality in palliative care provision. However, it is disappointing that it makes no reference to improve diversity, equality, and inclusion in palliative care. The current model of palliative care is not culturally competent.

"Once we really start to reflect upon the way our population is changing and meeting the needs of all different communities within palliative care, we will be in a much better place."

Etkind SN, Bone AE, Gomes B, etal. How many people will need palliative care in 2040? Past trends, future projections and implications for services. BMC Med 2017;15:102. doi: 10.1186/s12916-017-0860-2. https://bmcmedicine.biomedcentral.com/articles/10.1186/s12916-017-08602\#citeas. pmid: 28514961

2 Cicely Saunders International. You matter because you are you: an action plan for better palliative care. Jan 2020. https://csiweb.pos-pal.co.uk/csicontent/uploads/2021/01/Cicely-Saunders-Manifesto-A4-multipage_Jan2021-2.pdf.

3 Gomes B, Calanzani N, Gysels M, Hall S, Higginson IJ. Heterogeneity and changes in preferences for dying at home: a systematic review. BMC Palliat Care2013;12:7. doi: 10.1186/1472-684X-12-7. https://bmcpalliatcare.biomedcentral.com/articles/10.1186/1472-684X-12-7. pmid: 23414145

4 The Choice in End of Life Care Programme Board. What's important to me: a review of choice in end of life care. Feb 2015. https://assets.publishing.service.gov.uk/government/uploads/system/uploads/attachment_data/file/407244/CHOICE_REVIEW_FINAL_for_web.pdf. 